\title{
O cinema de Quentin Tarantino e suas três principais formas de representação: as cenas do cotidiano, os momentos exploitation e o jogo num cinema de gênero paródico \\ Mauro Baptista
}

\section{RESUMO}

Este artigo trata das três principais formas de representação do cinema de Tarantino identificadas pela análise, que o autor nomeia como cenas do cotidiano, momentos exploitation e jogo. O artigo trata também da forma como o cineasta lida com o cinema do passado, utilizando a intertextualidade para criar um cinema de crime pós-moderno instigante.

\section{ABSTRACT}

This article deals with the three fundamenal forms of remesentation of Quentin Tarantino's films, which the author names as scenes from do quotidian, exploitation moments and game. The artick also studis's the approach the filmmaker has with the cinema of the past, using parody to create a powerful postmodern cinema. 


\section{Os três conceitos fundamentais do cinema de Tarantino}

Neste artigo gostaria de apresentar os três modos de representação que constróem a heterogeneidade pós-moderna do cinema de Tarantino: o que denomino cenas do cotidiano, os momentos exploitation e o jogo. O cinema de Tarantino surge da oscilação entre esses três modos de representação que implicam notórias mudanças de tom e provocam reações de natureza diversa no espectador, como o horror, o riso e a cumplicidade. O ecletismo, o enciclopedismo e a abundante utilização e assimilação de influências cinematográficas presentes nos filmes de Tarantino levou-me a pensar nestes conceitos no esforço de conseguir uma melhor compreensão de um cinema heterogêneo, complexo e ambíguo por excelência.

$O$ fato de identificarmos essas três formas não significa que surjam necessariamente de modo isolado. O gênero de crime é o universo comum onde se alternam e combinam cenas do cotidiano, os momentos exploitation e o jogo. Uma cena como a tortura do policial (Reservoir Dogs) parte de uma situação do gênero de crime, deriva para a sinceridade cruel de Mr. Blonde (Michael Madsen), as súplicas do policial, para surpreender e chocar o espectador (a violência dos filmes exploitation), na combinação de tortura, música e dança. A saída noturna de Vincent (John Travolta) e Mia (Uma Thurman) em Pulp Fiction, reúne a metaficção genérica do ambiente retro, cheio de citações do cinema e da música do passado, com o realismo da conversa do casal, construída com digressões dos personagens e tempos mortos. Gostaria de definir o que é o cinema exploitation: numa definição abrangente, são filmes de baixo orçamento feitos fora da indústria - seja a americana, ou as oscilantes indústrias brasileira e/ou argentina - que mostram mais violência, sexo e drogas do que a produção majoritária. No Brasil, a pornochanchada, os filmes de Zé do Caixão, a produção da Boca do Lixo, foram típicos casos de cinema exploitation; na Argentina, os filmes eróticos kitsch dirigidos por Armando Bo (talvez um Ed Wood argentino) e protagonizados pela escultural Isabel Sarli são outro exemplo. Para estudar Tarantino, prefiro me concentrar numa definição mais restringida do termo: exploitation films, produções independentes americanas de baixo orçamento das décadas de 50, 60 e 70, que atraíam o público com doses maiores de violência e sexo que as mostradas pela indústria Hollywood. ' De certa forma, Tarantino efetuou com os exploitation uma reapropriação similar à realizada por Truffaut e Godard com o cinema de gênero americano, em particular com a série $B$ (grande parte do film noir é B). Como a série B do final da década de 50, os 
exploitation films eram até pouco tempo atrás ignorados pela crítica e pelos produtores culturais. Por outro lado, não podemos desconhecer as diferenças entre a série B e os exploitation, de qualidade e de status, dado que os fiłmes $B$ eram realizados dentro da indústria, com orçamentos baixos para Hollywood mas muito superiores às cifras dos exploitation. A série B permitiu a muitos diretores passar a realizar filmes de grandes orçamentos. Isto ocorreu com muito menor frequiência no caso dos exploitation (Jonathan Demme é uma exceção. fez o exploitation Caged Heat). Um dos grandes diretores do exploitation dos anos 70, Jack Hill, é ainda um ilustre desconhecido para o grande público; não assim os dois maiores produtores independentes. Roger Corman e Samuel Arkoff. '

\section{Cenas do cotidiano}

"O ponto inicial é o seguinte: você tem personagens de gênero em situaç̧̃es de gênero que você já assistiu em outros filmes, mas, de repente, sein razão aparente, eles são colocados em regras da vida real." 3

Ao ler a declaração de Tarantino, o leitor poderá se perguntar: de que tipo de vida real ele está falando? O cineasta satura o fil me de crime de referências à cultura pop, de hábitos de consumo cotidianos, de brincadeiras e piadas sobre sexo, com o humor como potencial contraponto irônico. Por cultura pop entendo o conjunto de subculturas de massa como a música ligeira, as séries de televisão, o cinema de ação, a cultura da droga. ${ }^{+}$Tarantino mescla uma situação típica do gênero de crime com aspectos próprios do banal, do rotineiro, do lado prosaico da vida. Essa situação híbrida sofre uma virada repentina, provocada pelo acaso. que detém o avanço lógico da trama, para criar um aparente hiper-realismo que rapidamente passa a ser absurdo e irreal (o tiro na cabeça de Marvin, a overdose de Mia, em Pulp Fiction; o decepamento da orelha, o sangue de Freddy em Reservoir Dogs). A estratégia baseia-se numa inversão das prioridades do gênero. Aspectos que anteriormente eram secundários são agora principais, em detrimento da história central do gênero. Em lugar de realismo, estamos perante uma magnificação do banal e do acidental. Qualifico o foco no banal e rotineiro do cinema de Tarantino como cena do cotidiano, essencialmente diferente da representação naturalista de Hollywood, que busca a aparência de reál.

A passagem do gênero ao lado prosaico da vida pode ser provocada por irrupção de um acontecimento imprevisível, pela ação 
irracional de um personagem ou pelas digressões dos personagens nos diálogos, que giram fundamentalmente em torno de cultura $p o p$, sexo, drogas e consumo. No cinema de Tarantino, a cultura pop faz parte do lado prosaico da vida da mesma maneira que atividades rotineiras como consumir fast-food, dirigir um automóvel em Los Angeles ou ir ao banheiro. Trata-se do cotidiano de Los Angeles, um lugar onde a vida real está permanentemente influenciada e permeada pela indústria cultural, cinematográfica, televisiva e musical.

O consumo presente em Reservoir Dogs, Pulp Fiction ou Jackie Brown é constituído fundamentalmente por hábitos de baixo custo acessíveis à maioria da população ${ }^{5}$ : escutar música, ver televisão, ir ao cinema, comer num fast-food e consumir maconha. As preferências de cada personagem definem sua personalidade e a capacidade de comunicar-se com o outro.

Em Reservoir Dogs e Pulp Fiction as cenas do cotidiano, o alongamento dos tempos dos personagens, funcionam como quebra e contraponto de situações e personagens típicos de um filme de crime. Já em Jackie Brown, ambas as formas de representação coexistem, sem as mudanças bruscas dos filmes anteriores.

Vejamos algumas das incursões do cena do cotidiano no universo do filme de crime. Nessa enumeração desejo constatar a saturação do gênero por elementos cotidianos apresentados em aparência como realistas:

- Em Reservoir Dogs vemos personagens do universo do crime que falam de Madonna, de dar ou não dar gorjeta, de séries de televisão, de música pop, de filmes e atores, da diferença entre as mulheres negras e brancas, de comprar maconha, de escutar programas de rádio; que fazem piadas e brincam o tempo todo (sobre sexo especialmente), que não querem se chamar Mr. Pink ou Mr. Brown pelas conotações de homossexualismo e excremento; um assaltante ( $\mathrm{Mr}$. Blonde) que depois de um assalto pára para comprar um sanduíche.

- Em Pulp Fiction, vemos criminosos entusiastas do fast-food (comida rápida), um chefe mafioso que sai para comprar donuts, dois assassinos que discutem o significado sexual de uma massagem nos pés, como se consome drogas na Holanda, as diferenças entre hábitos de consumo de fast-food na Europa e nos Estados Unidos, um boxeador que arrisca a vida para recuperar um relógio de ouro da família, um assassino que vai ao banheiro com um gibi para ler, o mesmo assassino que morre porque vai ao banheiro e deixa a metralhadora na cozinha, o dono de uma casa de penhora e um policial que torturam e estupram, um assassino que compra heroína de um amável traficante 
(que parece um estudante de classe média), o mesmo assassino que sai com a mulher do chefe e pergunta o preço de um milk shake. a mulher que confunde heroína com cocaína e tem uma overdose, um assassino cuja pistola dispara por acidente e mata um jovem sujando de sangue um carro, a dupla de assassinos que limpa o sangue do carro. A isso se somam várias referências a séries de televisão, fïlmes de gênero e música rock e pop.

- Em Jackie Brown, não faz sentido a enumeração, porque a cena do cotidiano é a forma dominante. Aí não é o gênero de crime que se impregna de realismo cotidiano, há uma interação de ambos os elementos num mesmo nível, com oscilações em que o cotidiano da vida de Los Angeles predomina sobre cenas próprias do gênero de crime e vice-versa.

\section{Exploitation e Cinema de Atraçōes}

Ao gênero de crime e às cenas do cotidiano, Tarantino agrega momentos de extrema violência, sexo bizarro e drogas, que chocam e agridem o espectador. Momentos que, graças à paródia e ao humor negro. provocam emoções contraditórias e freqüentemente simultâneas, como o horror e o riso. Reações diversas, que pela ambivalência proposital das cenas, dependem bastante do estado de espírito do espectador." Tarantino cria essa ambivalência que desconcerta o espectador de duas formas: por um lado, opera rápidas e constantes mudanças de tom, por outro, exibe a violência lançando ao mesmo tempo um olhar irônico e distanciado sobre a cena. São duas operações simultâneas sobre um mesmo momento do filme.

Esses momentos de violência e vulgaridade suspendem o avanço da cadeia linear-causal de eventos, caraterística central do cinema clássico, e atraem a atenção do público, independentemente de sua função narrativa. Como Tarantino se compraz estendendo os tempos (da cena, dos planos) para além do convencional, prolonga o momento violento e mórbido ou a conversação vulgar com uma vontade manifesta de perturbar e sacudir a audiência. Vejamos alguns exemplos:

- Quando Mr. White (Harvey Keitel) atira num radiopatrulha. vemos os policiais se retorcendo enquanto vão sendo perfurados pelas balas e o pára-brisas do carro que se empapa de sangue. numa demonstração exibicionista do horror.

Quando Mia está morrendo de overdose de heroína. Tarantino alentece os momentos anteriores à injeção de adrenalina no coração; a atração da cena evoca os filmes de terror, mais especificamente as produções italianas sanguinolentas de zumbis que o diretor admira. 
O encontro entre Mr. Blonde e Eddie (Chris Penn) dá lugar a uma série de piadas sexuais vulgares, com referências explícitas a homossexualismo nas prisões e estupros, que se prolongam além do tempo necessário para a função de caracterizar os personagens. Há nessas cenas um deleite com a agressão, com a surpresa, com a dilatação da duração do ato de violência ou da piada vulgar para além do esperado pelo espectador; há um jogo consciente do cineasta destinado a sacudir o público da letargia em que entrou nos anos 80 e. 90 . É o excesso e o senso de humor dos momentos de violência, sexo e drogas dos filmes exploitation dos anos 70 que inspiram Tarantino para criar suas cenas violentas e grotescas, que desconcertam e provocam riso no espectador, distanciando-o da trama. Os filmes exploitations interrompiam a narrativa linear e causal de seus subgêneros ${ }^{8} \mathrm{com}$ passagens de violência, sexo e em menor medida, consumo de drogas. $O$ foco da obra de Tarantino se volta para os exploitation films da década de 70 (até 75-76), que além de mostrar violência com excesso e morbidez, incorporavam a cultura da droga e a música pop pouco respeitável, e, vale destacar, tratavam o sexo com uma liberdade e humor que não se encaixavam na moral da indústria. Defino as cenas agressivas, exibicionistas e chocantes de Pulp Fiction e Reservoir Dogs como "momentos exploitation"." Tarantino é o primeiro diretor de magnitude que incorpora os exploitation films a um projeto de ci104 nema pós-moderno criativo.

Afirmo que os momentos exploitation de Tarantino pertencem à tradição lúdica do cinema de atrações, conceito desenvolvido por Tom Gunning para estudar um cinema não narrativo dos primeiros tempos. ${ }^{10}$ O cinema de atrações, modo dominante até 1906-07, não teve como prioridade contar uma história, mas sim mostrar imagens excêntricas que chocavam, provocavam surpresa e divertiam o público. No começo do século, a experiência do público nesse tipo de filmes assemelhava-se antes às atrações de uma feira ou circo do que ao teatro de "qualidade".!" Gunning extrai o termo atração do artigo de Sergei Eisenstein sobre um novo modelo para o teatro. Atração para Eisenstein é todo elemento que submeta o espectador a uma ação sensorial ou psicológica com o propósito de produzir nele certos choques emocionais. ${ }^{2}$ Antiilusionista, a atração lembra continuamente $o$ espectador que ele está vendo um espetáculo. Gunning assinala que, apesar da supremacia do cinema narrativo, o cinema de atrações ainda persiste como forma secundária, e ".parte essencial do cinema popular". ${ }^{13}$ A estética das atrações pode não dominar todo um longametragem, mas. "fornece uma corrente subterrânea que flui șob a narrativa lógica e o realismo diegético". ${ }^{14}$ 
O monento exploitation é uma atração no sentido de Gunning; é uma das principais estratégias do cinema de Tarantino para interromper o transcurso da história linear em direção a um objetivo, além das digressões e da divisão do filme em segmentos autônomos (micro-relatos). Outro procedimento que suspende o envolvimento do espectador é o jogo.

\section{Jogo}

Os filmes de Tarantino recorrem a vários procedimentos para distanciar o espectador da fíç̧ão. São técnicas que marcam o caráter ficcional da representação e deflagram um efeito de descolamento do espectador da história, apresentada como jogo e não como espelho do real. Entre as técnicas utilizadas podemos destacar:

Letreiros que definem o significado de "pulp" no início do filme: letreiros com o nome dos personagens em caracteres brancos sobre tela preta (Reservoir Dogs). letreiros com o nome das histórias, ou caracteres sobre a imagem fotográfica, informando o tempo e o lugar da ação (Pulp Fiction e especialmente Jackie Brown).

Fade In/Fade Outs. Momentos em que a tela fica preta e há um instante de silêncio. Pausas na narrativa.

Voz Over nos créditos, de um locutor de rádio e de Freddy (Reservoir Dogs).

Voz Off em créditos, inclusive nos créditos da companhia produtora; de personagens (Reservoir Dogs, Pulp Fiction).

Música: proveniente de um programa de rádio (Reservoir Dogs), ou com ruído de movimentação do dial (Pulp Fiction). Em Jackie Brown. a canção inicial começa sobre o selo Band Apart, a produtora do diretor.

Elementos lúdicos e excêntricos, não naturalista, como o quadrado que Mia Wallace (Ving Rhames) desenha no ar, ou a paisagem em branco e preto projetada no táxi que leva o boxeador Butch (Bruce Willis) em Pulp Fiction).

Câmera lenta combinada com música. Na sequência pré-créditos de abertura de Reservoir Dogs (os assaltantes caminham pela rua), no estupro de Marsellus Wallace (Pulp Fiction).

O jogo e distanciamento na performance dos atores, que desempenham um duplo papel: mostram-se como atores e como personagens.

Distanciamento e jogo na decupagem, com posições de câmera que evidenciam sua presença. com perspectivas que limitam o campo de visão, com posições de câmera afastadas dos atores.

Os personagens situados em posições quase geométricas, não-rea- 
listas, como no vasto galpão de Reservoir Dogs.

Nas roupas arti:iciais, estudadas, não naturalistas dos personagens. O paletó, gravata preta e camisa branca dos assaltantes, o aspecto de membro de gangue do policial Holdaway (Randy. Brooks) em Reservoir Dogs, o paletó e o corte de cabelo de Jules (Samuel Jackson) e Vincent (Pulp Fiction), o gorro e a trança de cabelo de Ordell (Jackie Brown) .

As técnicas que distanciam o espectador podem criar, em certas ocasiões, passagen: de metaficção, no sentido de imagens não do mundo, mas imagens que a comunicação construiu para representar esse mundo. ${ }^{15}$ Quando o boxeador Butch escolhe a espada. de samurai e desce a escada em posição de combate, o filme joga com imagens típicas de filmes de artes marciais e, por que não, de Toshiro Mifune em Yojimbo (1961) e Os Sete Samurais (1964) de Kurosawa. Quando a imagem de Pumpkin (Tim Roth) e Honey Bunny (Amanda Plummer) com as armas empunhadas se congela, evoca similar procedimento de freeze frame em The Bad, the Good and the Ugly (1968), de Sergio Leone. Quando Jackie (Pam Grier), aeromoça, percorre o aeroporto ao som da música soul "I10 Street", de Bobby Whomack, os ecos dos filmes blaxploitation dos anos 70 dominam a imagem. Quando Mia Wallace desenha um quadrado no ar, recordamos procedimentos da primeira fase de Godard, em especial o minuto de silêncio que os personagens e a narração fazem em Bande Apart.

A metaficção implica evocar, citar, aludir, parodiar obras do passado. Tarantino parte de histórias e técnicas presentes em outros filmes e marca diferenças e distância. Essa tarefa pode ser englobada sob a noção ampla de paródia, na perspectiva desenvolvida por Linda Hutcheon.

\section{Tarantino e a relação com o cinema do passado: paródia, pastiche e jogo}

Hutcheon trabalha o conceito de paródia dentro de um projeto intelectual que pensa o pós-moderno como força criativa. ${ }^{16}$ Para Hutcheon, a paród:a é uma das formas mais importantes da autoreflexividade. É repetição com diferença, intertextualidade com distância e ironia. $^{17}$ Hutcheon amplia o significado da paródia, desvinculando-o da companhia obrigatória do cômico e do riso. Para a autora, nem toda paródia é ridicularizadora, nem toda referência a um texto anterior é uma paródia, como atestam os conceitos de imitação, citação e pastiche. Diferente da citação, a paródia trabalha tanto no nível da obra a ser parodiado quanto no do código da obra que utiliza 
a paródia. Portanto, na paródia existem dois textos em jogo. o citado e o contraponto irônico.

Os filmes de Tarantino adotam uma postura lúdica em relação ao cinema de passado e a si mesmos. É um cinema pós-moderno criativo, que se vale da paródia, em oposição a um cinema pós-moderno conservador, apegado a uma depauperação do cinema clássico, à citação sem diferença e ao pastiche. Hutcheon indica como "a paródia procura de fato a diferenciação no seu relacionamento com o modelo, o pastiche opera mais por semelhança e correspondência $[\ldots]$ a paródia é transformadora no seu relacionamento com outros textos: o pastiche é ihilativo". "is Um filme pós-moderno que se baseia no pastiche não esiabelece a diferença e evita tratar o presente, preferindo evocar um passado cinematográfico mítico. É uma prática a-críticá. um mero exercício de cinefilia nostálgica e conservadora.

Tarantino trabalha com filmes, gêneros e formas de fazer cinema, com uma distância crítica que incorpora a referência ao tempo presente do filme que realiza. Se em Jackie Brown Tarantino evoca a Califónina dos anos 70 , é porque se preocupa com a visão que se tem dessa época no tempo presente. Como os personagens que viveram ativamente aqueles anos estão hoje, no final da década de 90 , na cidade de Los Angeles? Se em Pulp Fiction ele alude a diversas épocas do filme de crime, é para olhar com ironia e reformular o gênero; é para mostrar como vários pressupostos do cinema do crime do passado não continuam necessariamente vigentes. como, por exemplo, a femme fatale, à paranóia, a cidade ameaçadora.

$O$ fato de retomar o cinema do passado e marcar uma diferençá a paródia com distância criativa revela que Tarantino tem um ponto de vista pessoal e próprio. É dentro dessa revisão criativa do passado que podemos valorizar em seus filmes a permanência de questõeschave do gênero, como a confiança, a ética, a lealdade. Aspectos que não estão presentes nos filmes como meros significantes do gênero, mas como produto de um processo que reformula o gênero desde uma perspectiva contemporânea. Quentin Tarantino repensa o passado à luz da época em que concebe seus filmes.

\section{Notas}

1 Nos anos 70, filmes como Coffy, Foxy Brown e The Big Doll House, I protagonizados por Pam Grier e dirigidos por Jack Hill. referência fundamental do cinema de Tarantino, chocavam e divertiam o público, que os assistia em drive-ins (cinemas ao ar livre em que os filmes eram assistidos nos automóveis) e salas pouco respeitáveis. 
$2 \mathrm{O}$ exploitation apoiou-se em subgêneros como os filmes de prisão feminina, de gargues, de motoqueiros, de terror, de ficção científica, e o blaxploitation (exploitations protagonizados por afro-americanos na primeira metade da década de 70 ), que recriava fundamentalmente o amplo universo genérico do filme de crime, dividindo-o em subgêneros como o filme do traficante, do proxeneta.

3 G. Smith, When You Know You're in Good Hands, op. cit. p. 100

4 Cultura que se caracteriza pelo hábito de grande parte da sociedade contemporânea de consumir drogas, especialmente maconha, haxixe e cocaína.

5 Encontramos algumas excepções, como Vincent Vega (Pulp. Fiction) que compra heroína a 500 dólares o grama, seu carro Malibu e os traficantes que compram armas em Jackie Brown.

$6 \mathrm{Um}$ exemplo pessoal: a cena em que Mr. Blonde corta a orelha do policial me chocou muito na primeira vez que vi o filme, ao ponto de quase deixar de olhar para a tela, algo que muito raramente faço. Na segunda vez que a vi já estava preparado, e percebi algumas risadas, talvez nervosas, na sala. Na terceira vez pude perceber totalmente o subtexto humorístico mórbido da cena, o contraponto entre a tortura, a dança e a música pop, e dei algumas 108 risadas.

7 Por exemplo, Zombie (1980) e The Gates of Hell (1981) de Lucio Fulci, diretor italiano reconhecido no gênero de terror, que alguns críticos denominan "giallo".

80 exploitation apoiou-se em subgêneros como os filmes de prisão feminina, de gangues, de motoqueiros, de terror, de ficção científi$\mathrm{ca}$, sem falar do blaxploitation (exploitations protagonizados por afro-americanos na primeira metade da década de 70), que recriava fundamentalmente o amplo universo genérico do filme de crime, dividindo-o em subgêneros como o filme do traficante, do proxeneta.

9 Enquanto estudava os momentos de exibição agressiva dos exploitation filns s como The Big Doll House, não pude deixar de pensar em compará-los com os procedimentos de agressão ao espectador do cinema marginal, que Fernão Ramos relaciona com uma proposta estética brechtiana que agride o espectador como elemento de conscientização. Nos exploitation films há certamente uma maior preocupação em contar uma história de forma clássica, o que contrasta com a maior agressão e desconstrução nar- 
rativa do cinema marginal. Ver Fernao Ramos. Cinema Marginal (1968/1973): a Representação em seu Limite. Brasiliense, São Paulo, 1987.

10 Tom Gunning, "The Cinema of Attractions - early film, its spectator and the avant-garde". In: Thomas Elsaesser (ed.), com Adam Barke. Early Cinema: Space. Frame, Narrative, Londres, British Film Institute, 1990.

$11 \mathrm{lbid}$., p. 58.

12 Serguei Eisenstein. "Montagem de Atrações". In: I. Xavier (org.). A Experiencia do Cinema, Rio de Janeiro, Graal, 1983.

13 T. Gunning. "O Cinema das Origens e o Espectador (In) crédulo". In: Imagens, Ed. Unicamp, n. 5, Agosto-Dezembro 1995, p. 60.

14 lbid., p. 50

15 Dennis Mellier, "Discours de Tueurs: Fragmentation et Perturbation dans Natural Born Killers d' Oliver Stone. Précedé d'une Remarque à Propos de Quentin Tarantino". In: Gilles Menecaldo (org.), Crises de la Représentation dans le Cinéma Americain. UFR/Langues Littératures, Poitiers, 1996, p. 228.

16 Ver Linda Hutcheon, Poética do Pós-modernismo. Imago, Rio de Janeiro. 1991.

17 Idem, Uma Teoria da Paródia. Edições 70. Lisboa, 1989. p. 54.

18 lbid., p. 55.

\section{Palavras chave:}

1. cinema de crime

2. Tarantino

3. paródia

4. films exploitation

5. intertextualidade 
